\title{
No, World-System, Cogito Interruptus ${ }^{1}$
}

\section{Sebastião Guilherme Albano}

Professor Adjunto do Departamento de Comunicação Social e do Programa de Mestrado em Estudos da Mídia (PPgEM) da UFRN. Pós-doutor pela Universidad Nacional Autónoma de México e The University of Texas at Austin.

\footnotetext{
${ }^{1}$ Artigo produzido durante o pósdoutorado na Universidad Nacional Autónoma de México com bolsa da Capes.
}

Resumo: Em face da emergência de um modelo de análise do cinema inspirado na teoria do sistema-mundo de Fernand Braudel e Immanuel Wallerstein, elaboramos uma reflexão acerca do filme NO (Pablo Larraín, 2012), em que vinculamos a circunstância histórica de sua matéria-prima temática, o plebiscito de 1988 no Chile, com a da feitura do filme. Comparamos aspectos relativos à política e à poética a fim de aventar um diagnóstico desse filme como articulação retórica de enunciados sociais que atravessaram os últimos quatro decênios a fomentarem um padrão de interpretação e imaginação de longo alcance temporal e com muita influência na esfera pública que provoca uma espécie de cogito interruptus.

Palavras-chave: Cinema mundial; world-system; NO; política; estética.

Abstract: Based on the emergence of cinema analysis models related to the World-System theory by Fernand Braudel and Immanuel Wallerstein, we built a reflection on the Chilean movie NO (Pablo Larraín, 2012) that includes both the historical circumstances of the movie plot, which is the 1988's Plebiscite, and the context in which the movie was produced. We compare political and poetical issues in order to suggest that the film is a rethorical articulation of some social contents which have been in the spotlight throughout the last four decades and enable long term interpretative and imaginative patterns.

Keywords: World Cinema; World-System; NO; Politics; Aesthetics.

Refletiremos acerca do filme NO (Pablo Larraín, 2012), cujo mote tem origens no golpe de estado perpetrado pelas forças armadas chilenas em 1973, início de uma ditadura de quinze anos. Sua fábula, malgrado invoque a história o tempo todo, ressalta mesmo um ponto de vista sobre o plebiscito de cinco de outubro de 1988 convocado pelo governo de facto para legitimar sua atuação. Em razão dos sinais memorialistas que apresenta (afinal, Larraín é filho de políticos de direita e, tal qual René, o protagonista interpretado por Gael García Bernal, seu pai teve participação ativa no debate sobre a ditadura e a transição; além disso, o filme tem uma granulagem de época devido ao uso da tecnologia analógica U-matic, comum até inícios de 1990; aparecem ou se escutam figurões da resistência como Patrício Aylwin, o jornalista Patricio Bañados, o sociólogo Eugenio Tironi, o músico Carlos Cabezas, além de Isabel e Tita Parra, entre outros; há estratégias de reportagem etc.), pode-se crer se tratar de um documento atravessado por uma subjetividade que traça e vocaliza o que se vê e se ouve. Mas não, ao menos no sentido que lhe atribui a esse modo documental bem exercitado na região (Quem bom te ver viva, Lúcia Murat, 1989; Los rubios, Albertina Carri, 2006; Sibila, Teresa Arredondo, 2012; Elena, Petra Costa, 2012). 
Por certo, coincide uma impressão geral que deixam o filme e o processo que culminou com o fim do despotismo de Augusto Pinochet, uma vez que nas duas esferas foi imperativo o referendo externo para se consolidarem. Restringindonos às teorias sociais que desenham o mundo como um sistema, ambos os eventos atestam, como exemplares, o caráter dependente e mesmo subalterno do regime político-econômico e do regime expressivo chileno e latino-americano. Sob esse foco particular, no que tange à história e à economia-política, ressaltase o quadro da Guerra Fria e as manobras dos Estados Unidos para derrocar os intentos socialistas no mundo inteiro, e no caso de Salvador Allende (como em tantos outros) a alternativa foi substituí-lo por um oficial fiel, Pinochet (Suharto, Castelo Branco, Costa e Silva, Massera, Saddam Hussein), mantê-lo a fim de fazer uma reforma conservadora do estado e um decênio e meio mais tarde, quando a orientação neoliberal é preponderante e necessita sobremaneira de seu braço democrático para embalar a nova litania dos direitos humanos, apoiar um grupo, la Consertación, que grosso modo estava/está composto por homens e mulheres de esquerda hoje convencidos, não sem um longo doutrinamento, que o centro é a única posição plausível (uma nova Realpolitik). A propósito do campo expressivo (logístico e retórico/poético), abandonaram-se os esquemas mais ou menos caseiros (nacionais?) de arranjo iconográfico e de produção em prol de apoio multinacional (coproduções) com consequências estéticas importantes, porquanto boa parte dos filmes latino-americanos agora se vincula ao chamado world cinema (NAGIB, 2005). Em nenhum desses campos e em momento algum houve com efeito protagonismo dos agentes regionais envolvidos, desde sempre enquadrando-se na conjuntura da dependência ou, se melhor convier, na lógica do world-system (WALLERSTEIN, 1974; 1979).

Tocaremos mais nessa corda. Ao advogar uma mesma origem e um mesmo destino para a geopolítica, as ciências humanas e a imaginação poética (como já registrara BRAUDEL, 1958; 1987), afinal componentes da esfera pública, a noção de world-system enseja réplica, comentários e epígonos. Outra vez: tanto em seu sentido político (o mundo é um sistema em que a economia move as relações de poder; países centrais projetam ideias e produtos para países periféricos), como em seu sentido retórico, aí importando para nós seu viés de world cinema (parte do sistema-mundo, em que a economia subvenciona os valores, os filmes de países centrais infundem normas aos de países periféricos), a noção de world cinema funciona para dar conta de determinados fenômenos produzidos em e por NO. Manejaremos, portanto, alguma terminologia dos estudos de literatura comparada contemporâneos (SPIVAK, 2003; MORETTI, 2001; 2011; TANOUKHI, 2011), resgatando seu elã para a crítica ao relativismo cultural e sobretudo à imobilidade do cânone estético. Essa perspectiva requer de uma visada em escala, no nosso caso, às vezes recorrendo ao procedimento e às conclusões proporcionadas por uma observação próxima (algo como o close reading, uma leitura detalhada de uma ou poucas peças, ou uma leitura realizada a partir da proximidade cultural), outras invocando as observações panorâmicas que talvez nos remetam à distant reading (MORETTI, 2000; 2013). Como fizemos em outras ocasiões, deixaremos constância de que a elevada incidência da cronotopia histórico-política nas discursividades da região desde o século XIX tem o condão de revelar certo pendor para a autoanálise (ALBANO, 2011) e o vezo da semiose infinita.

\section{A Mnemosine, o mentecapto e o cogito interruptus}

Um ponto que no decorrer do filme ganha corpo é a cantilena crítica (sarcástica) por parte de René aos códigos retóricos mais ostensivos da comunicação política tradicional, projetando-nos contudo a uma mistificação corrente à época do plebiscito, quando as consignas do pós-político e mesmo do apolítico campeavam às largas nas falas das vanguardas do pensamento social. Não obstante, o subtexto que se divisa na mirada vaga e fria do protagonista, encarnação do pragmatismo, relaciona-se com a emergência de uma sensibilidade política diversa da anterior. 
No início da narrativa, a sequência em que René e Urrutia (Luis Gnecco) vão jantar pela primeira vez, o jovem publicitário pensando em tomar um ônibus e o velho camarada socialista a preferir um taxi, em qualquer país da América Latina funciona como uma sinalização acerca das coordenadas éticas que devem ser observadas a partir dali.

Com efeito, o ethos da sociedade retratada no filme, espelhado em uma idealização da sociedade chilena, com construções conflituosas, mas com soluções esperançosas (os longos anos democráticos anteriores ao golpe, algo incomum na região, e o alto nível de politização dos chilenos; o tipo de socialismo democrático propugnado por Salvador Allende; o apelo das mães dos desaparecidos etc.), sinaliza mudança. $\mathrm{E}$ as mensagens da comunicação social devem renovar-se a fim de se adaptarem a uma audiência, a uma massa, a uma multidão reformada e agora, por paradoxal que possa parecer, tão somente munida de retalhos de recordações da história recortados pelas técnicas de reinterpretar os fatos próprias da mídia, cujo objetivo o filme deixa entrever ser mesmo o de alcançar o monopólio da voz e com isso a vantagem pecuniária.

Sem se importar demasiado com suas incongruências, consciente de suas contradições, para René essa tarefa de desmemória (RICHARD, 2000) e encerramento da história em uma interpretação consensual e una deveria ser promovida a partir de uma nova coleção de imagens, joviais e festivas, que se sobrepusessem ao repertório anterior, gris e calcado na reflexão e no sofrimento, referido pelo publicitário como vitimista e enfadonho. Em prol do voto pelo NO, o plebiscito é considerado um produto ou um case ao qual deveriam ser agregados valores positivos no sentido teledramatúrgico, publicitário, mercadotécnico, isto é, apagar a dor como foram apagados os rastros dos desaparecidos políticos e substituí-la por esperança. Ou como diz Fernando Arancibia (Néstor Cantillana), um dos marketers envolvidos na campanha do NO, substituí-los por felicidade pura, pois não existe nada mais feliz do que a felicidade...

Essa preferência pelo nonsense inscrita nesse axioma episódico paira sobre todo o filme e pode ocasionar desconforto devido à anarquia que se desenha como apoio argumentativo, sensação que recrudesce quando ouvimos nas três peças que René apresenta a mesma advertência: "o que vocês verão está circunstanciado no quadro social contemporâneo. A sociedade chilena já está preparada para uma comunicação dessa natureza". E o que o espectador assiste é sempre ao mesmo complexo retórico em que abundam signos que, nesses casos específicos, forçam o relevo do conteúdo mediante a mudança do significante, como se tal manobra fosse possível sem que o todo fosse revisado (uma campanha de propaganda política em forma de publicidade comercial; a chamada de uma telenovela em simbiose com as notas do noticiário noturno). Em fins dos anos 1980 na América Latina grassaram essas experiências de vazio existencial promovidas entre a opinião pública (no sentido marxista de ser o resultado da apresentação de uma opinião privada como se compartilhada e pública), cujas consequências deletérias foram as eleições de grandes histriões para a presidência de várias repúblicas regionais: Carlos Menem, Alberto Fujimori e Fernando Collor de Melo são exemplos contumazes. A despeito dessas figuraças difíceis de ser emuladas, o binômio política e marketing vige nas campanhas eleitorais e institucionais mundo afora e como é de conhecimento de todos, engendra monstros.

A pretensão de instalar uma memória por intermédio dos meios muitas vezes leva a olvidar que a transição no Chile foi penosa, em um registro pouco usual na mídia, lugar em que o sofrimento se revela com uma plasticidade incompatível com a dor humana, e secundariza também o fato de que até pouco tempo houve, da parte dos militares, imposições tão demonstrativas de poder como o fato de as três forças manterem autonomia de decisão em relação ao legislativo, judiciário e executivo, de haver designação de senadores ao congresso, entre outras anomalias 
que impedem, se tomamos NO como uma leitura da história chilena, considerar o filme apenas um verniz cool ao projeto reacionário. $\mathrm{O}$ entramado que a película apresenta aposta nas ambiguidades morais que se incrementam quando:

1. Vemos René trabalhar na agência de Chucho Guzmán (Alfredo Castro), um reconhecido aliado do regime e quem sugere inclusive, quando começa a intuir a derrota do Sí, o desaparecimento físico dos envolvidos com o NO e, em um momento climático do filme, faz ameaças a Simón (Pascal Montero), filho de René, e que isso não cause rompimento da amizade ou da relação trabalhista que eles mantêm.

2. Somos guiados a estender seus prognósticos estéticos e éticos para o campo da história, tarefa muito difícil de evitar, quase impossível, ao se deparar a posição da empregada Carmen (Elsa Poblete) a simbolizar mesmo o torpe esquecimento de uma parcela da população, uma classe social talvez, promovido pela mensagem cotidiana dos meios acerca da necessidade de deixar o passado para trás, esquecer. Carmen insinua votar no SI porque seus filhos têm trabalho e estudam.

3. Hesitamos em perceber que a ignorância que no filme se the atribui a Pinochet acerca do resultado do plebiscito é um ardil diegético tal como a indignação discreta de Guzmán quando René Ihe diz que agora os Estados Unidos apoiam o NO, revendo sua posição em relação ao papel das forças armadas e da ditadura. Por seu turno, René diz ao princípio que a peça publicitária do refrigerante Free encerrava novidades expressivas que, em caso de haver paralelo no mundo, apenas seria encontrado na América (nos Estados Unidos). Como se desconhecesse a proveniência daquele modelo.

Esses dados apenas funcionam como verdades no mundo arquitetado no filme e em seus lugares (topoi) conceituais. Na vida real, a equipe de marqueteiros do NO sabia a origem daqueles signos que ali reproduziam, bem como todo o primeiro escalão do governo Pinochet sabia que o Sí sucumbiria e que a convocação do plebiscito tão só asseguraria uma transição menos brusca do que aquela que o colocou no poder e de quebra criaria condições de barganhar algum privilégio para os seus.

A título de contraponto, importa recordar a série de documentários anteriores a NO dirigidos por Patricio Guzmán. Em La batalla de Chile. La insurrección de la burguesía (1975), La batalla de Chile. El golpe de estado (1977), La Batalla de Chile. El poder popular (1979) e em La memoria obstinada (1997), o regime de imagens provoca um movimento de reflexão inverso ao de NO. Esse efeito não é suscitado porque os filmes estão armados com uma clara visão favorável às forças socialistas, mas sim porque nessa operação sobressai um caráter de espontaneidade testemunhal que não compreende todas as faces do embate. Não há nenhum filme, digamos, de direita, que possa mostrar ações semelhantes às desses documentários, com uma posição de defesa de uma verdade que não se embarace na ironia ou em outro subterfúgio. Os filmes encomiásticos do nacional socialismo germânico da primeira metade do século XX não querem se aproximar à espontaneidade, tampouco são irônicos e tão só parecem perseguir abstrações sublimes. Por outras vias, algo próximo aos filmes de Guzmán ocorre com $A$ autobiografia de Nicolae Ceausescu (Andrei Ujica, 2010), em que dita espontaneidade das imagens em relação às ações do presidente romeno combinam com seus depoimentos ao tribunal que o condenou à pena capital. Mas tamanha coerência se desfaz ao final quando de súbito descobre-se que essa espontaneidade se trata de uma burla, uma encenação documental de sua versão dos fatos, uma ficcionalização de autoparódia que em verdade é uma paródia. Outra paródia, mas desta vez compactuada com o espectador e a anuência dos parodiados aparece no recente The Act of Killing (Josh Oppenheimer, 2013). Militares e paramilitares responsáveis por um massacre em 1965/1966 na Indonésia aceitam, com espírito de chacota, atuarem em um filme acerca do genocídio de aproximadamente um milhão de pessoas. 
No caso de $A$ batalla do Chile, as imagens apresentam-se como um fluxo intransigente que visa conformar uma tese acerca da truculência dos grupos conservadores, especialmente a primeira parte, quando ao final a voice over revela que um dos camarógrafos que filmou as manifestações que precederam o golpe, o argentino Leonardo Henrichsen, acabou registrando sua própria morte à bala em junho de 1973. Os tiros que o militar disparou em sua direção visavam intimidar um profissional que filmava uma agressão a um jovem caído. Esse grau do testemunho, de demonstração, de materializacão é a norma em La batalla..., com alta voltagem de denúncia, séria, direta e só equiparada em películas comprometidas com algo fora do cinema, mas a que o cinema serve. $O$ que não ocorre nos mesmos termos com NO, e tampouco é sua intenção. Portanto, dentre os diagnósticos que se possam atribuir ao filme, não cabe considerá-lo um documento factual e sim uma obra de invenção e, devido ao tema da fábula mais o tom empregado, a conclusão moralizante que poderíamos tirar é a de que há um olhar cínico e complacente com o ocorrido no país que representa. E talvez seja esse um grande valor, mostrar-se claramente como um artifício ético, moral e estético por intermédio de figuração radical da ambiguidade. Apoia esta assertiva o momento em que no filme o experiente socialista levanta-se indignado depois de ouvir de seus companheiros argumentos favoráveis ao colorido programa que René lhes apresentou para a campanha do NO. Tudo nos leva a pensar naquela ala da esquerda revolucionária que se crê nunca coadunou com a inexorável flexibilização visual que a linguagem propagandística, ou o estilo televisivo corrente então, confere aos sentimentos de pesar e repugnância. Verónica, a combativa esposa de René, mãe de Simón e interpretada por Antonia Zegers, também expressa sua revolta com aqueles códigos. Mas essas são exceções de transparências emocionais em meio a um universo tão opaco como a aversão de Urrutia a ouvir que o termo democracia é utilizado como se correspondesse a um produto, mas sua anuência às novas estratégias de marketing utilizadas na campanha do NO. Essa opacidade campeia ao longo do filme e se apresenta como o grande desafio retórico da narrativa.

Nessa mesma seara de interações entre fábula, discurso e o mundo da vida, em 2013 o golpe militar no Chile fez 40 anos e certamente o mundo em que podemos recordar a efeméride parece outro, muito embora certos procedimentos e discrepâncias sociais permaneçam intocados. É possível encontrar muitas Verónicas nas manifestações contemporâneas, mas uma espécie de padrão midiático desses novos jovens revoltados relativiza sua credibilidade, ao menos até lograrem criar um novo modelo de revolta e expressão dessa revolta. Não que essa atitude nunca tenha sido objeto de sublimação, basta recordar a influência social de $O$ vermelho e o negro (1830) com o ambíguo e carismático Julien Sorel, ou Os miseráveis (1962) e Jean Valjean (neste caso, Victor Hugo foi alçado a herói nacional) e Guerra e Paz (1869) e seus vários heróis russos contra Napoleão. Mas hoje a boa disposição com o espetáculo per se acrescido dos mitos e fatos que circundam a capacidade de convocação multitudinária das redes sociais não coopera para a legitimacão de suas ações.

História, memória e recordação são mecanismos com os quais atualizamos um tipo de evento, sendo que o primeiro termo está contaminado pela acepção de imobilidade, o segundo pela imprecisão do movimento constante e o terceiro por seu caráter físico: a recordação é um fragmento subjetivo, mas material, e é engrenado pela memória. Por seu turno, desde sempre os atos de comunicação inspiram o uso de tecnologia para armazenar dados a fim de melhor manuseá-los quando for a ocasião. A comunicação é código, assim como toda linguagem é uma convenção. Não é fortuito que Deleuze (1995) considere que na origem dos alfabetos descanse um intuito de domínio e poder. Na atualidade, a modalidade de memória ativada pelos meios de comunicação em aparência pluraliza as versões, mas na prática as instituições que representam o formato social em que o capitalismo aparece mais como um projeto de civilização do que um regime 
econômico controlam a sintaxe e a semântica dos fatos. A opinião de Nelly Richard acerca do arranjo televisivo para a transição política chilena merecer ser levada em consideração, especialmente porque sugere um embate entre a Mnemosine e um mentecapto:

La televisión chilena -metamorfoseada por el full-color de un registro de estetización publicitaria que sólo demanda presencias lisas- ha suprimido de sus pantallas, mediante fluidos procedimientos de obliteración visual, los cuerpos y las identidades dañadas que no aceptaron maquillarse con la cosmética del bienestar y sus modas de la entreteción. El retrato en blanco y negro de los detenidos-desaparecidos ya no combina con nada en medio del cromatismo exacerbado de esta festividad de logotipos y estereotipos que sumerge diariamente el reclamo de la desaparición en la brutal anacronicidad de signos de algo ya pretérito. Es como si el desgaste de fotocopia pobre y reviente de su grano en blanco y negro estuvieran delatando, frente a los brillos de la contemporaneidad mediática, el retraso visual de una vergonzante incopetencia del lenguaje que termina así de inactualizar el drama político en medio de este paisaje -neoliberal- de imágenes relucientes que gozan inmoralmente con la sobreexposición de sus brillos (RICHARD, 2008: 175).

Uma espécie de vingança da memória, como a parte viva da história, ocorre toda vez que os eventos se repetem e demonstram que as formas sociais são finitas, mas se replicam às vezes em outras regiões e em outros tempos, conclusões da teoria da evolução das espécies aplicada à ordem social. Os próprios meios de comunicação, com seu arrivismo atávico, esquecem os retratos morais que elaboram e reelaboram sem muito critério nítido que não o da manutenção de poder. Decerto, essa recorrência obedece à lógica dos ciclos e das modas (parte da efetividade dos meios está baseada na repetição das mensagens, em sazonalidades), e os recortes mais plásticos ou mais obscuros de um evento traumático são retomados e reelaborados constantemente, gerando uma espécie de cogito interruptus (ECO, 1995), traduzido por Fernand Braudel como longue durée (em termos gerais, a longa duração é um valor de análise que prioriza eventos históricos que tem uma influência que atravessa fronteiras regionais e desdobra-se ao longo de um amplo período de tempo, como o capitalismo, os estados nacionais). Eventos como as duas grandes guerras europeias do século XX, ficcionalizadas, estetizadas, enfim, rememoradas ad infinitum pelos discursos da indústria cultural como se fossem as únicas e como se fossem iguais, impossibilitam a dedicação de tempo midiático às guerras africanas e asiáticas, por exemplo, apenas enfocadas por uma grande angular paternal e antropológica. Em NO, mais de uma vez se menciona (Verônica fala a René, René fala a Guzmán etc.) essa parecença entre as campanhas que se apresentam e se insinua a anulação das energias propulsoras das ações políticas mais arrojadas quando confrontadas com uma mídia cuja função social parece ser precisamente desinformar, contrainformar, anuviar. NO retoma o tema do estado totalitário chileno e lhe imprime um registro de indecisão estética e ética que reabre a discussão a partir de novas chaves interpretativas, incendiando uma das estações da semiose infinita (cogito interruptus).

Outros momentos podem igualmente delatar uma escassez de soluções, como se supõe em uma primeira leitura, mas cremos que antes mostram tão somente o espaço de ação em que eles acreditavam ser possível preparar a campanha, estabelecido pelos limites do neoliberalismo. Por exemplo, a orquestração narrativa, do tipo leitmotiv, das sequências relativas às atitudes de imitação recíproca entre René e Guzmán e salientada por terceiros personagens. René apropria-se do espírito publicitário de Guzmán, Guzmán do espírito marqueteiro de René: copia de la copia de la copia de la copia de la copia, opina Verónica uma vez, depois René faz o mesmo referindo-se aos esforços de Guzmán de modernizar a campanha do Sí. Outro momento em que essa contingência do generalizado uso de fórmulas pragmáticas se mostra de maneira anafórica é quando René termina 
de apresentar suas campanhas a executivos ou políticos. Sem importar a formação e o flanco ideológico a pergunta é sempre a mesma: Isso é tudo? Acabou? É só isso que tem para mostrar? A mesma atitude ele toma quando vê a campanha que a equipe do NO fazia antes de ele ser convocado. Na economia narrativa e semântica do filme, essa simetria comportamental conota ainda a isonomia de posições diante de fenômenos que o senso comum vê como antagônicos, mas que não passam de circunstâncias de embate pelo controle da enunciação. A culminância dessa mixórdia semântica e moral parece ser quando um grupo de mulheres de esquerda grava uma canção para a campanha e alguém da produção diz: façam como We are the world (relativo à campanha USA for Africa, que em 1985 juntou vários nomes da música para arrecadar fundos contra a fome no continente). As moças reclamam, demonstram indignação até eles voltarem atrás, mas ao final o clipe ficou muito parecido ao norte-americano. Cabe o registro de que no Canadá a canção Tears are not enough, teve um propósito e um clipe similar e no Brasil no mesmo período se fez algo muito semelhante na campanha Nordeste já! e também com o clipe da canção Viver outra vez, em que músicos se reuniram para granjear fundos para as pesquisas em busca de alternativas para a Aids.

No esquema sistema-mundo aqui referido a recuperação constante de formas e conteúdos pretéritos e seu reprocessamento e apresentação reiterada como se se tratasse de algo natural e inevitável tem uma razão bafejada pela ordem geopolítica e econômica. A viravolta ética e moral é mesmo uma constante do filme (Urrutia prefere táxi a ônibus, mas não suporta que se trate a democracia como um produto; René aceita presentes de Guzmán, trabalha para ele, mas se engaja no NO; as imitações descaradas), daí que sua relutância em assumir uma identidade que reivindique a diferença se nos depara o ponto forte da película, cínica estética e ideologicamente, e nos dá ensejo para comentar o que denominamos crise da representação em sociedades fraturadas pelo trauma, o que resulta em uma crise de valores em geral. Como preâmbulo, não poderíamos deixar de ao menos tocar nos célebres comentários de Adorno acerca do aplacamento do gosto poético depois de Auschwitz, e de Benjamin a propósito das misérias humanas que a história tende a trazer à tona em modo de ruína a ser reconstruída, mas que os ventos do progresso desarranjam constantemente em mostra de sua rejeição ao confronto com um passado concreto que não seja produto da sua invenção e da sua destruição. 0 que dizer dos discursos literários e fílmicos na América Latina depois de um milhão de mortos deixados pela Revolução Mexicana? E depois da crueldade das guerras intestinas na América Central? E depois do 11 de setembro chileno?

\section{Crise da representação, escala e distant reading}

Talvez livros como A era do vazio (Gilles Lipovetsky), A condição pós-moderna (Jean-François Lyotard; David Harvey) e a anunciada transformação dos paradigmas (Foucault, Lyotard, etc.) condensem os enunciados que apoiam a verossimilhança de NO. Interessa pouco se é proposital ou não, o fato é que o mundo projetado no filme está permeado por um punhado de consignas que foram hegemônicas na academia e nos meios de comunicação (a esfera pública) entre fins de 1970 e fins de 1980, isto é, logo antes de que outras proposições quase tão abstratas ganhassem mais fôlego e se desdobrassem: sociedade da informação, sociedade do conhecimento, globalização. Aquele momento hoje recordado como de impasse no pensamento ocidental e na vida do mundo todo pode ilustrar a ideia de crise da representação (Nietzsche, Heidegger, Foucault), que resume as duas séries de enunciados e as processa como transição cognitiva e emocional do quadro de legitimação política, sobretudo das democracias liberais e dos estados nacionais, atingindo em cheio os modos discursivos que debatem e publicitam seus programas. As noções de mimese e verossimilhança, termos de um contrato entre obra e leitor ou espectador, estrutural nas narrativas e nas descrições, donde fundamento dos romances, contos, telenovelas, filmes, reportagens e notícias, foram tão questionados nos séculos XIX e XX que resultaram na cada vez 
mais acelerada sucessão de denominações de correntes literárias e pictóricas e almejam dar conta dos cambiantes códigos representativos, mas assinalam um sintoma de ansiedade. Resulta curioso que a representação dual (significante + significado ou vice-versa) desfez-se no plano da autorrepresentação do sujeito, que relativizou sua centralidade na enunciação do mundo e multiplicou-se, ocasionando instabilidade na sensibilidade estética, por si mesma resvaladia, e no pensamento ético. Não obstante, o quadro aparentar o oposto a dialética como circuito de relação entre contrários segue pertinente sempre e quando não culmine em síntese (no campo cultural, a ideia de hibridismo é uma cria desse movimento sintético, fluida como explicação instrumentalizada de qualquer procedimento cultural com base na influência ou mesmo na intertextualidade, enforcando uma reflexão menos calculada).

Em NO, o momento político e as modalidades de figuração propostas pelos envolvidos em sua feitura (especialmente Pablo Larraín) suscitam uma sensação de fastio com a realidade anterior, que supomos ser a dos anos que imediatamente precederam a ditadura e os quais ela vigorou. Os personagens mesmo dizem e algumas imagens de arquivo aparecem como um espectro dissonante para nos assombrar ao tempo em que nos contextualiza e familiariza com o dia onze de setembro de 1973, quando as forças armadas invadiram o Palacio de la Moneda e deram cabo de Salvador Allende. Esse procedimento reduz a distância entre o passado e o presente do filme (fábula e discurso) e em paralelo subtrai as dificuldades de reconhecimento, uma vez que uma audiência mais ou menos adulta (entre 20 e 50 anos) não terá problema para identificar de que se trata, ainda sendo um espectador africano, asiático ou do extremo norte da Europa. Uma tal angulação por Moretti, Spivak e Tanoukhi definida de escala $(2001 ; 2003 ; 2011)$ é uma precondição importante para a fruição de filmes latino-americanos fincados nas idiossincrasias locais (relativas à denúncia social) universalizadas pelas formas discursivas (outra conclusão instrumental que merece revisão). Convém recordar que em NO esse estar fora de lugar é um traço estilístico e diegético porque logra fazer o filme estranho aos latino-americanistas puro sangue, que acreditam em essências locais, e trivial para as elites globalizadas, que ali confirmam algumas de suas teses. Mas uma leitura dialética de alguns planos textuais de NO Ihes atribuiria um teor de revisão dos termos da mimese e da representação por estarem como que atravessados pela dubiedade da matéria política que resgata.

NO opera também como um catalisador da necessária atualização representativa do Chile e do cinema do país, integrando-o a uma comunidade cultural específica, à qual um pouco ironicamente poderíamos chamar de comunidade do Oscar ou comunidade dos festivais, aquela que o prêmio da academia de cinema dos Estados Unidos e os festivais europeus representam. Essa escala em que se apoia o filme, isto é, a possibilidade de que em sua textura estejam implicados, como representação mimética, alguns anos de política internacional e de embates retóricos, dimensiona a funcionalidade das discursividades modernas e contemporâneas (literatura, fotografia, cinema, games) ao se reportarem a um tipo de mundo anterior ou posterior ou mesmo externo às obras, ressignificando-o com uma reconstrução dos fatos por outros canais e com outras dimensões, ressignificando-o em escala. Mesmo sendo tão afeito à dialética e às imagens de árvores genealógicas (ramificações, etc.) para descrever os processos de formação da literatura brasileira, em vez de escala, Antonio Candido (2011) define esse procedimento como uma serventia da estrutura literária (fílmica) à veiculação de uma função histórica, ao que nós acrescentaríamos que o contrário também seria pertinente. Filmes como NO de ordinário dão a dimensão também do caráter instrumental que podem adquirir certas obras ao solicitar coletividades por intermédio de uma dúzia de signos intersubjetivos, subvencionados pela mímese rasteira que as instituições neoliberais produzem (SARLO, 2009), tal como as estatísticas, os índices, as declarações dos conclaves do G8, do G20 e, decerto, os vereditos dos festivais. Nesse sentido, NO é um espelho a refletir o curso de 
uma crise de representação política, social e estética de fins do século XX latinoamericano, mas um espelho que não duplica traços físicos ou psicológicos e os certifica, senão os delineia em imagens que estimulam a indagação.

É certo que NO erige-se como um filme típico (tipo) do world cinema e que segue a tradição da world literature abraçada por Moretti (2011), quem nos promete que também na periferia se representa "the world as a totality" (2011: 67), imagem explicativa concernente à teoria do world-system, que concebe o mundo como "unified, but inequal" (2011: 68). Não parece a intenção de Moretti, talvez mais diplomático em suas sentenças, mas as estrelinhas de suas assertivas (o mundo como totalidade, unificado, mas desigual), se confrontadas a filigranas morais de $N O$, fazem constar que se a distância geográfica que suscita a diversidade de formas que poderia obstruir a apreciação de um espectador desavisado desaparece, por conta do sistema de economia-mundo que percebe o cinema como uma commodity, a crise de representação nesses países periféricos torna-se cada vez mais afiada (no filme fica patente nas palavras de René depois de assistir à peça publicitária que a equipe do NO estava fazendo antes de ele ser convidado: eso no vende). Igualmente, é fato que essa racionalidade geométrica (extensão das redes midiáticas de distribuição/exibição e verticalização das diferenças) afinal dá conta de uma incompatibilidade na ordem das trocas ao materializar práticas e conteúdos que de hábito se julgam provindos do espírito e destinados a ele. Não obstante, não aparenta ser casual que essa linha da literatura comparada se embase tanto na teoria da evolução das espécies de Darwin, com sua visada diacrônica, como no conjunto de proposições do sistema-mundo, que tende à sincronia (herança da concepção da longue durée de Braudel).

Então, a ordem da escala fílmica suaviza a divergência histórica e a distância geográfica que poderiam fazer de NO um filme de pouca penetração nas audiências de países ocidentais mais desenvolvidos economicamente e com regimes políticos sem grandes percalços para a democracia representativa ou participativa. O world cinema é precisamente uma classificação compreensiva do fato de outros meios de comunicação e outras discursividades unificarem os dados intelectivos inscritos na diegese ou na composição das imagens para franquear a fruição ao espectador, já familiarizado com os estereótipos latino-americanos. NO favorece uma distant reading (panorâmica, com poucas especificidades, comparativa) por seu contato com certa transigência moral e com o deslocamento cultural calculado de fins do século $X X$, atributos da pós-modernidade sublimados no terceiro mundo. Mas esse cálculo ao fim corrobora seu pendor estilístico pelo falso documental ao querer projetar-se como um microcosmo do regime poético e político que se desenha com a tinta da teoria do sistema-mundo, uma vez que o filme emite sinais de identidade com aquele clima planetário, mas o espiritualiza com um par de peculiaridades angustiantes do fin de siècle na América Latina. Em NO o referido cruzamento de tradições e discursividades pode até isentar o filme de criar a fim de que lhe sobre tempo para sobreviver em um universo supercodificado, como insinua Moretti (2000), mas a dita isenção aparece na obra da mesma maneira determinante e libidinal que a espontaneidade atribuída por nós a La batalla de Chile de Patricio Guzmán, portanto, a isenção é um dado estilístico de monta.

Esse sinal de identidade, em que sobressai o embate entre as acepções etimológica e social do termo, com efeito torna idênticas até as peculiaridades, pois se o percurso e os vícios políticos regionais podem ser denominados idiossincrasias latino-americanas, quando mirados através da lente da pós-modernidade adquirem um definitivo condicionamento com o centro do mundo (cinismo, pragmatismo, individualismo, homogeneização cultural pela globalização) o que não é necessariamente um resultado positivo ou negativo. Como referido, tal como as peças publicitárias do refrigerante Free, da campanha do $N O$ e do projeto de lançamento da telenovela que aparece ao final, NO simboliza um esforço de identificação, mas aquele que nas palavras de Nirvana Tanoukhi (2011) 
apenas pode ser enunciado como um deslocamento. "The language of alternative modernity thus disguises a real dissonance between an academic thesis that celebrates the periphery's specificity, and a local outlook that experiences 'specificity' as a mark of inferiority" (2011: 89). Essa ânsia de adequação flagrante na película resulta em uma discrepância entre o que dizem e o que fazem os personagens remarcando, pela estranheza dialética, o acerto narrativo em que as aparências escondem mais do que mostram. Em NO há poucas manifestações de incômodo (Verónica, o político que se irrita com a mensagem positiva) a respeito de se saber outro em um mundo com desigualdade crescente ao mesmo tempo em que as distâncias se encurtam, o que no filme traduz-se na ausência daquela ansiedade da influência e na relevância que adquire a quimérica propagandística de fim da diferença e idealização da norma.

Em termos muito simplistas, o world cinema supõe a sincronização das cinematografias nacionais cujos dêiticos culturais e o mobiliário iconográfico foi absorvido, para não utilizar o termo ultrapassado, pela máquina diacrônica da história da evolução dos gêneros e reprocessada na sincronia do longo presente da obra cinematográfica, que alinha em seu espaço a miríade de tradições formais que convoca. Ademais, o processo de construção do espaço nos filmes, ainda quando se representam lugares tão exóticos como os áridos morros peruanos (Madeinusa, Claudia Llosa, 2006), os canais filipinos (Lola, Brillante Mendoza, 2009) ou os vilarejos medievais europeus (Fausto, Alexander Sokurov, 2011), passa pelos formatos da espetacularização que os esquemas dominantes de composição estabelecem, mediante a escala.

Em boa parte das obras que se inscrevem no world cinema, se o tomamos como um gênero, tem-se a impressão de que a produção de espaços se retrai para franquear a reprodução de espaços-tipo, mais afeitos à elucidação e menos à simbolização. Quando há força criadora, em geral se manifesta mediante uma manobra descritiva no momento de dar visibilidade aos componentes do espaço, que sempre tem uma tradição fílmica. Em parte do world cinema há inclinação por uma apropriação e produção espacial que frisa o abjeto dos cenários cotidianos, ainda quando pareçam exóticos como as selvas que convivem e ameaçam o urbano, os morros áridos que cercam as cidades ocidentalizadas e assim por diante. Em NO é dentro dos esquemas de espacialização da cidade (ruas arborizadas por onde transita com seu skate um René meio alienado e meio cool; sua casa aconchegante e pequeno burguesa; o bairro, o prédio e o apartamento lúgubres e solidários em que Verónica vive com seu novo esposo comunista) e dos interiores dos lares, dos escritórios e dos settings publicitários em que se tensionam valores como cinismo, individualismo, relaxamento moral, crise da representação estética e política, homogeneizacão cultural e se experimentam as figurações neoliberais e pós-modernas. A república do cinema evocada em NO (CASANOVA, 2004) é uma pátria pós-nacionalista em que a vida tem certa densidade própria, ainda que sujeita aos pesos e medidas da teoria do world-system. Em todo caso, NO subverte com certa leveza a sentença de Moretti (2000) acerca da instabilidade do projeto poético das literaturas e cinematografias do terceiro mundo em favor da urgência de compromisso social.

\section{Considerações finais}

A etiqueta world cinema funciona como um prólogo intelectivo no momento em que nos deparamos com determinados filmes com características que se querem diversas às de Hollywood. Mais do que apenas um gênero que denota a existência de outras espacialidades e territorialidades, esse termo congrega uma denominação geopolítica cujo traço relevante é a relação de dependência, em face da desequilibrada penetração dos filmes norte-americanos no âmbito da distribuição e da exibição em boa parte do mundo e a insignificante parcela de filmes do mundo no mercado norte-americano (MORETTI, 2001). A despeito de 
parecer demonstrar uma disposição à provincianização dos Estados Unidos e da Europa, world cinema submete o restante da produção mundial ao código das relações econômicas que estabelece uma divisão do trabalho planetária, inclusive de cunho pós-nacional, sugerindo um campo de atuação da cosmopolítica (ALBANO, 2010). Isso porque, dentro dos próprios estados nacionais, notadamente naqueles que a duras penas ainda são considerados centrais como a França, a Alemanha e a Inglaterra, há quase que somente duas modalidades de filmes a serem produzidos para exibidos em salas de cinemas: um em formato comercial (o global de Hollywood, comédias ou filmes de ação), e outro, às vezes com abundante número de imigrantes em seus quadros, em que as temáticas, a iconografia e os modos de produção confinam com o de regiões mais distantes. 0 que se vislumbra como uma reação à hegemonia é em verdade uma naturalização de um prefixo cujo emprego hoje dá a impressão de querer validar certas práticas civilizadoras e culturais. Veja-se por exemplo o termo world music, exprimindo uma ideia de cosmopolitismo do gosto ao mesmo tempo em que encobre o fato de a universalização dos procedimentos de produção da sonoridade emitida significarem uma pasteurização que atende às necessidades de comercialização de um mercado que é simultaneamente globalizado e provinciano. O filme NO também sintetiza um pouco esse paradoxo cultural por intermédio de uma fabulação da história política de um país que foi um dos laboratórios do neoliberalismo (ANDERSON, 2009: 216).

Aos 40 anos do golpe militar no Chile, NO, ao encenar os bastidores da campanha do plebiscito que franqueou o retorno ao chamado estado de direito, adquire mais de uma engrenagem a dar-lhe sentido. Reflete esse modo de produção surgido depois do Consenso de Washington, uma vez que se mostrou transnacionalizado a partir mesmo de sua captação de recursos. Projeta um mundo atualizado no registro neoliberal que vicejava em 1989 e que hoje se declara vencedor, porquanto naturalizado em constituições nacionais, nos estatutos dos organismos internacionais e no padrão de produção cultural, especialmente naquelas discursividades hospedadas em suportes como o cinema. Por fim, demonstra as ambiguidades que essas duas últimas consequências têm de propalar para que o modelo sobreviva. Como referido, ainda não parece possível uma representação dos meandros éticos e estéticos do neoliberalismo sem que uma tonalidade pelintra, irônica porque desencantada, subverta até as melhores intenções dos envolvidos no projeto. NO deixa explícita uma tal impossibilidade até mesmo com a trilha sonora, que combina jingles com Brahms, cuecas com Sibelius, fixando sua inspiração dialética na acepção materialista proposta por Engels (1940) em sua revisão desse método (a de um espaço para a interpenetração dos contrários), mas sinalizando variedades menos abstratas ou local dialectics como remarca Jameson (2009).

Para ilustrar o procedimento de local dialectics, no campo dos gestos políticos figurados pela diegese de $N O$, definindo essa noção como o movimento em que um fragmento da história social é esclarecido pelo pensamento cinematográfico, tomese a sequência em que o marqueteiro argentino encarregado da campanha do Sí e interpretado por Pablo Krögh faz um discurso de convencimento aos quadros militares do governo a fim de que Pinochet apareça na televisão sem uniforme para que a população do país apenas se lembre das benesses econômicas do neoliberalismo e relegue as atrocidades. Nos planos que se sucedem em ritmo ansioso há duas mensagens mais ou menos subliminares que enriquecem nossas teses acerca da importância das tensões entre o visível, o falado e as ações dos personagens na constituição de NO. A primeira diz respeito a que os militares terão de se resignar e assumir que foram instrumentalizados (a guerra é a extensão da política) pelos interesses geopolíticos e econômicos externos que hoje não mais os necessita. A segunda quase mostra que em verdade para os agentes desses interesses já não mais importa quem governe o país, se Pinochet em trajes civis ou um opositor da Consertación, pois sua agenda conservadora já está institucionalizada. 


\section{Referências bibliográficas}

ALBANO, Sebastião Guilherme. "Cosmopolítica, mídia e a virtualização da América Latina." Revista da Associação Nacional dos Programas de Pós-Graduação em Comunicação. E-compós, Brasília, v.13, n.2, maio/ago. 2010, p.1-15.

"Intertextos: ensaio, romance e mídia na modernidade latino-americana." Animus. Revista Interamericana de Comunicação Midiática. Santa Maria, v.10, n.19, 2011, p. 58-75.

BRAUDEL, Fernand. "Histoire et sciences sociales: La longue durée." Annales. Histoire, Sciences Sociales (October - December 1958), p. 725-753.

; COLL, A. “Histoire et sciences sociales: La longe durée." Réseaux. 1987, p. 7-37.

CANDIDO, Antonio. Literatura e sociedade. 8.ed. São Paulo: T. A. Queiroz, 2000.

CASANOVA, Pascale. The World Republic of Letters. Trad. De M.B. DeBevoise. Cambridge/Londres: Harvard University Press, 2004.

DELEUZE, Gilles; GUATTARI, Félix. Mil platôs. Capitalismo e esquizofrenia. Vol. 1. Trad. Aurélio Guerra Neto e Célia Pinto Costa. Rio de Janeiro: 34, 1995.

ECO, Umberto. La estrategia de la ilusión. Trad. de Eduardo Oviedo. Barcelona: Lumen, 1995.

ENGELS, Friedrich. The Dialetics of Nature. Nova York: International Publishers, 1940.

JAMESON, Fredric. The Valences of Dialects. Londres/Nova York: Verso, 2009.

MORETTI, Franco. “Conjectures on World Literature”. New Left Review 1, JanuaryFebruary 2000, p. 54-68.

“Planet Hollywood”. New Left Review 9, May-June 2001, p. 90-101.

"World-Systems Analysis, Evolutionary Theory, Weltliteratur". In: PALUMBOLIU, David; ROBBINS, Bruce; TANOUKHI, Nirvana (Edts). Immanuel Wallerstein and the Problem of the World. System, Scale, Culture. Durham/Londres: Duke University Press, 2011, p. 67-77.

NAGIB, Lúcia. "Towards a Positive Definition of World Cinema". In: LIM, Song Hwee; DENNISON, Stephanie (orgs). Remapping World Cinema: Identity, Culture and Politics in Film. Londres: Wallflower Press, 2005, p. 30-37.

RICHARD, Nelly. Políticas e estéticas de la memoria. Santiago: Cuarto Propio, 2000.

"Con motivo del 11 de septiembre de 1973: notas sobre La memoria obstinada (1996) de Patricio Guzmán". In: RICHARD, Nelly (Ed.). Debates críticos en América Latina, 3. Santiago: Cuarto Propio; Arcis, 2008, p. 175-181.

SARLO, Beatriz. "Contra la mímesis: izquierda cultural, izquierda política". In: RICHARD, Nelly (Ed.). Debates críticos en América Latina, 3. Santiago: Cuarto Propio/ Arcis, 2009, p.231-233.

SPIVAK, Gayatri C. The Death of a Discipline. Nova York: Columbia University Press, 2003.

TANOUKHI, Nirvana. "The Scale of World Literature". In: PALUMBO-LIU, David; ROBBINS, Bruce;

TANOUKHI, Nirvana (Edts). Immanuel Wallerstein and the Problem of the World. System, Scale, Culture. Durham/Londres: Duke University Press, 2011, p. 78-98. 
WALLERSTEIN, Immanuel. The Modern World-System I: Capitalist Agriculture and the Origins of the European World-Economy in the Sixteenth Century. New York: Academic Press, 1974.

The Capitalist World-Economy. Cambridge: Cambridge University Press, 1979. 